Research Article

\title{
Browder's Convergence Theorem for Multivalued Mappings in Banach Spaces without the Endpoint Condition
}

\author{
Thanomsak Laokul \\ Department of Mathematics, Faculty of Science Chiang Mai University, Chiang Mai 50200, Thailand \\ Correspondence should be addressed to Thanomsak Laokul; thanomsak_l@cmu.ac.th
}

Received 24 October 2019; Accepted 27 March 2020; Published 18 April 2020

Academic Editor: Kunquan Lan

Copyright (C) 2020 Thanomsak Laokul. This is an open access article distributed under the Creative Commons Attribution License, which permits unrestricted use, distribution, and reproduction in any medium, provided the original work is properly cited.

We prove Browder's convergence theorem for multivalued mappings in a uniformly convex Banach space with a uniformly Gâteaux differentiable norm by using the notion of diametrically regular mappings. Our results are significant improvement on results of Jung (2007) and Panyanak and Suantai (2020).

\section{Introduction}

Let $(E,\|\cdot\|)$ be a Banach space. We denote by $\mathscr{C} \mathscr{B}(E)$ the family of nonempty closed bounded subsets of $E$ and $\mathscr{K}(E)$ the family of nonempty compact subsets of $E$. For any nonempty subset $C$ of $E$ and $x \in E$, the distance from $x$ to $C$ is defined by

$$
\operatorname{dist}(x, C):=\inf \{\|x-y\|: y \in C\} .
$$

The radius of $C$ relative to $x$ is defined by

$$
R(x, C):=\sup \{\|x-y\|: y \in C\} .
$$

The diameter of $C$ is defined by

$$
\operatorname{diam}(C):=\sup \{\|x-y\|: x, y \in C\} .
$$

The set $C$ is said to be bounded if $\operatorname{diam}(C)<\infty$. The Hausdorff distance on $\mathscr{C} \mathscr{B}(E)$ is defined by

$$
H(A, B):=\max \left\{\sup _{a \in A} \operatorname{dist}(a, B), \sup _{b \in B} \operatorname{dist}(b, A)\right\} \quad \text { for all } A, B \in \mathscr{C} \mathscr{B}(E) .
$$

A multivalued mapping $T: C \longrightarrow \mathscr{C} \mathscr{B}(E)$ is said to be contractive if there exists a constant $k \in[0,1)$ such that

$$
H(T(x), T(y)) \leq k\|x-y\| \quad \text { for all } x, y \in C \text {. }
$$

If (5) is valid when $k=1$, then $T$ is said to be nonexpansive. It is clear that every contractive mapping is nonexpansive, but, in general, the converse is not true. A point $x \in C$ is said to be a fixed point of the multivalued mapping $T$ if $x \in T(x)$. We denote by $\operatorname{Fix}(T)$ the set of all fixed points of $T$. Additionally, if $\{x\}=T(x)$, then $x$ is called an endpoint (or a stationary point) of $T$. We denote by $\operatorname{End}(T)$ the set of all endpoints of $T$. We can see that for each mapping $T$, $\operatorname{End}(T) \subseteq \operatorname{Fix}(T)$. We may say in other words that the concept of endpoints seems to be more complicated than the concept of fixed points. Nevertheless, both concepts are coincident when $T$ is a single-valued mapping; in this case, $\operatorname{End}(T)=\operatorname{Fix}(T)$.

Let $T: C \longrightarrow \mathscr{K}(C)$ be a multivalued nonexpansive mapping. Given $u \in C$ and $t \in(0,1)$, let $G_{t}: C \longrightarrow \mathscr{K}(C)$ be defined by

$$
G_{t}(x)=t T(x)+(1-t) u, \quad x \in C .
$$

By Nadler's theorem [1], $G_{t}$ is a contraction and admits a fixed point $x_{t} \in C$, that is,

$$
x_{t} \in t T\left(x_{t}\right)+(1-t) u \text {. }
$$

If $T$ is single-valued, then

$$
x_{t}=t T\left(x_{t}\right)+(1-t) u \text {. }
$$


The strong convergence of the net $\left\{x_{t}\right\}$ for a singlevalued nonexpansive mapping $T$, which is defined by (8), has been investigated by many authors; especially in 1967 , Browder [2] established the great influence to the development of approximated fixed point theory. Some relevant definitions and concept will be given in the next section.

Theorem 1 (Browder [2]). Let $C$ be a nonempty bounded closed convex subset of a Hilbert space $H$ and $T: C \longrightarrow C$ be a nonexpansive mapping. Fix $u \in C$ and let $x_{t}$ be defined by (8). Then, $\left\{x_{t}\right\}$ converges strongly as $t \longrightarrow 1$ to the element of Fix $(T)$ nearest to $u$.

A natural question which arises is whether Browder's convergence theorem can be extended to the multivalued case. Pietramala [3] (see also Jung [4]) gave the following example which shows that it is not true in general.

Example 1. Let $C=[0,1] \times[0,1]$ be the square in the real plane and $T: C \longrightarrow \mathscr{K}(C)$ be defined by

$T(a, b):=$ the triangle with vertices $(0,0),(a, 0),(0, b) \quad$ for all $(a, b) \in C$.

It is easy to see that for any $\left(a_{1}, b_{1}\right),\left(a_{2}, b_{2}\right) \in C$,

$$
\begin{aligned}
H & \left(T\left(a_{1}, b_{1}\right), T\left(a_{2}, b_{2}\right)\right) \\
\quad & \max \left\{\left|a_{1}-a_{2}\right|,\left|b_{1}-b_{2}\right|\right\} \leq\left\|\left(a_{1}, b_{1}\right)-\left(a_{2}, b_{2}\right)\right\| .
\end{aligned}
$$

This implies that $T$ is nonexpansive. It is also easy to see that the fixed point set of $T$ is the set $\{(a, 0): 0 \leq a \leq 1\} \cup$ $\{(0, b): 0 \leq b \leq 1\}$. Let $u=(1,0)$; then, the mapping $G_{t}$ defined by (6) has the fixed point set $\operatorname{Fix}\left(G_{t}\right)=\{(a, 0): 1-$ $t \leq a \leq 1\}$. Let

$$
x_{t}= \begin{cases}(1 / n, 0), & \text { if } t=1-(1 / n) \\ (1,0), & \text { otherwise. }\end{cases}
$$

Then, $\left\{x_{t}\right\}$ satisfies (7), but it does not converge. This example also shows that the sequence $\left\{\operatorname{Fix}\left(G_{t}\right)\right\}$ does not converge as $t \longrightarrow 1$ to $\operatorname{Fix}(T)$ under the Hausdorff metric.

Pietramala [3] extended Browder's convergence theorem to the multivalued mapping case with the endpoint condition. Acedo and $\mathrm{Xu}$ [5] showed the strong convergence of the net $\left\{x_{t}\right\}$ defined by (7) in a Hilbert space under the endpoint condition. Later on, it was extended to a Banach space with a sequentially continuous duality mapping by Kim and Jung [6]. Sahu [7] proved the strong convergence of $\left\{x_{t}\right\}$ in a uniformly convex Banach space with a uniformly Gâteaux differentiable norm. Since then, the strong convergence of $\left\{x_{t}\right\}$ has been improved and many papers have appeared (see for instance [4, 8, 9]). Jung [4] provided the strong convergence of $\left\{x_{t}\right\}$ for a multivalued nonexpansive mapping in a uniformly convex or a reflexive Banach space having a uniformly Gâteaux differentiable norm. He also noted that the endpoint condition should be added in the main results of Sahu [7].

Theorem 2 (Jung [4]). Let E be a uniformly convex Banach space with a uniformly Gâteaux differentiable norm, $C$ a nonempty closed convex subset of $E$, and $T: C \longrightarrow \mathscr{K}(E)$ a multivalued nonexpansive mapping. Suppose that $C$ is a nonexpansive retract of $E$. Suppose that $T$ satisfies the endpoint condition and that for each $u \in C$ and $t \in(0,1)$, the contraction $G_{t}$ defined by (6) has a fixed point $x_{t} \in C$. Then, $T$ has a fixed point if and only if $\left\{x_{t}\right\}$ remains bounded as $t \longrightarrow 1$, and in this case, $\left\{x_{t}\right\}$ converges strongly as $t \longrightarrow 1$ to a fixed point of $T$.

Very recently, Panyanak and Suantai [10] brought the concept of diametrically regular mappings which is more general than the concept of the endpoint condition to prove Browder's theorem for multivalued nonexpansive mappings in Hadamard spaces.

Theorem 3 (Panyanak and Suantai [10]). Let $C$ be a nonempty closed convex subset of a Hadamard space $(X, \rho)$ and $T: C \longrightarrow \mathscr{K}(C)$ be a multivalued nonexpansive mapping. Fix $u \in C$ and let $\left\{x_{t}\right\}$ be defined by (7). Suppose that $\left\{x_{t}\right\}$ is diametrically regular for $T$. Then, $T$ has an endpoint if and only if $\left\{x_{t}\right\}$ is bounded as $t \longrightarrow 1$. In this case, $\left\{x_{t}\right\}$ converges strongly to the unique point $\tilde{x}$ in $\operatorname{End}(T)$ such that

$$
\rho(u, \tilde{x})=\min \{\rho(u, e): e \in \operatorname{End}(T)\} .
$$

In this paper, we will show that the result of Jung [4] in Theorem 2 can be approached without the endpoint condition by using the notion of diametrically regular mappings. Our results extend and complement many known results including those of $[2,4,7,10-12]$.

\section{Preliminaries and Lemmas}

Throughout this paper, $\mathbb{N}$ stands for the set of natural numbers and $\mathbb{R}$ stands for the set of real numbers.

Let $E$ be a Banach space and let $C$ be a nonempty subset of $E$. A multivalued mapping $T: C \longrightarrow \mathscr{C} \mathscr{B}(E)$ is said to be diametrically regular if there exists the net $\left\{x_{\alpha}\right\}$ in $C$ such that $\lim _{\alpha} \operatorname{diam}\left(T\left(x_{\alpha}\right)\right)=0$. In this case, we call $\left\{x_{\alpha}\right\}$ a diametrically regular net for $T$. The mapping $T$ is said to satisfy the endpoint condition if $T(y)=\{y\}$ for any $y \in \operatorname{Fix}(T)$. Notice that if $C$ is a nonempty closed convex subset of a uniformly convex Banach space $E$ and $T$ is a nonexpansive mapping, then $\operatorname{End}(T)$ is closed and convex (see [13]).

A Banach space $(E,\|\cdot\|)$ is said to be uniformly convex if for each $\varepsilon \in(0,2]$ there exists $\delta>0$ such that for any $x, y \in E$ the conditions $\|x\| \leq 1,\|y\| \leq 1$, and $\|x-y\| \geq \varepsilon$ imply

$$
\frac{\|x+y\|}{2} \leq 1-\delta
$$

It is well known that if $E$ is uniformly convex, then $E$ is reflexive and strictly convex (cf. [14]). The norm of $E$ is said 
to be Gâteaux differentiable (and $E$ is said to be smooth) if

$$
\lim _{t \rightarrow 0} \frac{\|x+t y\|-\|x\|}{t} \text { exists }
$$

for each $x, y$ in its unit sphere $S_{E}=\{x \in E:\|x\|=1\}$. It is said to be uniformly Gâteaux differentiable if for each $y \in S_{E}$, this limit is attained uniformly for $x \in S_{E}$. We denote by $J$ the (normalized) duality mapping from $E$ into $2^{E^{*}}$, i.e.,

$$
J(x)=\left\{x^{*} \in E^{*}:\left\langle x, x^{*}\right\rangle=\|x\|^{2}=\left\|x^{*}\right\|^{2}, x \in E\right\}
$$

where $\langle\cdot, \cdot\rangle$ denotes the generalized duality pairing.

A subset $C$ of $E$ is said to be a retract if there exists a continuous mapping $Q: E \longrightarrow C$ with $C=\operatorname{Fix}(Q)$. Any such mapping $Q$ is a retraction of $E$ onto $C$. If $Q$ is nonexpansive, then $C$ is said to be a nonexpansive retract of $E$ (cf. $[14,15])$.

Let $\mu$ be a linear continuous functional on $\ell^{\infty}$ and $a=\left(a_{1}, a_{2}, \cdots\right) \in \ell^{\infty}$. We will sometimes write $\mu_{n}\left(a_{n}\right)$ in place of the value $\mu(a)$. A linear continuous functional $\mu$ such that $\|\mu\|=1=\mu(1)$ and $\mu_{n}\left(a_{n}\right)=\mu_{n}\left(a_{n+1}\right)$ for every $a=\left(a_{1}, a_{2}, \cdots\right) \in \ell^{\infty}$ is called a Banach limit. We know that if $\mu$ is a Banach limit, then

$$
\liminf _{n \rightarrow \infty} a_{n} \leq \mu_{n}\left(a_{n}\right) \leq \limsup _{n \rightarrow \infty} a_{n}
$$

for every $a=\left(a_{1}, a_{2}, \cdots\right) \in \ell^{\infty}$. Let $\left\{x_{n}\right\}$ be a bounded sequence in $E$. Then, the real-valued continuous function $\phi$ on $E$ defined by

$$
\phi(z)=\mu_{n}\left\|x_{n}-z\right\|^{2}, \quad z \in E,
$$

is convex.

The following lemma was given in [16].

Lemma 4 (see [16]). Let $C$ be a nonempty closed convex subset of a Banach space $E$ with a uniformly Gâteaux differentiable norm and let $\left\{x_{n}\right\}$ be a bounded sequence in E. Let $\mu$ be a Banach limit and $u \in C$. Then,

$$
\mu_{n}\left\|x_{n}-u\right\|^{2}=\min _{y \in C} \mu_{n}\left\|x_{n}-y\right\|^{2}
$$

if and only if

$$
\mu_{n}\left\langle x-u, J\left(x_{n}-u\right)\right\rangle \leq 0
$$

for all $x \in C$.

The following result was essentially given by Reich [17] and also proved by Takahashi and Jeong [18].

Lemma 5 (see [18]). Let $E$ be a uniformly convex Banach space, $C$ a nonempty closed convex subset of $E$, and $\left\{x_{n}\right\} a$ bounded sequence in $E$. Then, the set

$$
M=\left\{u \in C: \mu_{n}\left\|x_{n}-u\right\|^{2}=\min _{z \in C} \mu_{n}\left\|x_{n}-z\right\|^{2}\right\}
$$

consists of one point.

From now on, we will use the notation $x_{n} \rightarrow x$ (resp., $x_{n} \longrightarrow x$ ) for a sequence $\left\{x_{n}\right\}$ converging weakly (resp., converging strongly) to a point $x$. The following two lemmas are also needed.

Lemma 6 (see [19]). Let $C$ be a nonempty subset of a metric space $E,\left\{x_{n}\right\}$ be a sequence in $C$, and $T: C \longrightarrow \mathscr{K}(E)$ be a multivalued mapping. Then, $R\left(x_{n}, T\left(x_{n}\right)\right) \longrightarrow 0$ if and only if $\operatorname{dist}\left(x_{n}, T\left(x_{n}\right)\right) \longrightarrow 0$ and $\operatorname{diam}\left(T\left(x_{n}\right)\right) \longrightarrow 0$.

Lemma 7 (see [20]). Let $C$ be a nonempty closed convex subset of a uniformly convex Banach space $E$ and $T: C \longrightarrow \mathscr{K}(E)$ be a multivalued nonexpansive mapping. Then, the following implication holds:

$$
\left\{x_{n}\right\} \subseteq C, x_{n} \rightarrow x, R\left(x_{n}, T\left(x_{n}\right)\right) \longrightarrow 0 \Longrightarrow x \in \operatorname{End}(T) .
$$

\section{Main Results}

We begin this section by proving that the diametric regularity of a nonexpansive mapping $T$ with a nonempty fixed point set is weaker than the endpoint condition. Our proof follows the ideas of proof in Panyanak and Suantai [10].

Proposition 8. Let E be a uniformly convex Banach space with a uniformly Gâteaux differentiable norm, $C$ a nonempty closed convex subset of $E$, and $T: C \longrightarrow \mathscr{K}(E)$ a multivalued nonexpansive mapping with $F i x(T) \neq \varnothing$. Suppose that $C$ is a nonexpansive retract of $E$ and that for each $u \in C$ and $t \in(0,1)$, the contraction $G_{t}$ defined by $G_{t}(x)=t T(x)+(1-$ $t) u$ has a fixed point $x_{t} \in C$. Then, the following statement holds:

$(\$)$ if $T$ satisfies the endpoint condition, then $\left\{x_{t}\right\}$ is a diametrically regular net for $T$.

Proof. By Theorem 2, $\lim _{t \rightarrow 1} x_{t}=\tilde{x}$, where $\tilde{x} \in \operatorname{Fix}(T)$. Since $T$ satisfies the endpoint condition, $\tilde{x} \in \operatorname{End}(T)$. For $v, w \in T$ $\left(x_{t}\right)$ we have

$$
\begin{aligned}
& \|v-w\| \leq\|v-\tilde{x}\|+\|\tilde{x}-w\| \leq \operatorname{dist}(v, T(\tilde{x})) \\
& \quad+\operatorname{dist}(w, T(\tilde{x})) \leq 2 H\left(T\left(x_{t}\right), T(\tilde{x})\right) \leq 2\left\|x_{t}-\tilde{x}\right\| .
\end{aligned}
$$

This implies that $\lim _{t \rightarrow 1} \operatorname{diam}\left(T\left(x_{t}\right)\right)=0$, and hence, $\left\{x_{t}\right\}$ is diametrically regular for $T$.

The following example shows that the endpoint condition in Proposition 8 is necessary. 
Example 2. Let $C:=[0,1], E:=\mathbb{R}$, and $T: C \longrightarrow \mathscr{K}(E)$ be defined by

$$
T(x)=[0,1+x] \quad \text { for all } x \in C .
$$

Then, $T$ is a multivalued nonexpansive mapping with $\operatorname{Fix}(T)=[0,1]$ and $\operatorname{End}(T)=\varnothing$. Since $\operatorname{diam}(T(x))=1+x$ for all $x \in C$, there is no net $\left\{x_{t}\right\}$ in $C$ which is diametrically regular for $T$.

The main theorem is proved as follows.

Theorem 9. Let $E$ be a uniformly convex Banach space with a uniformly Gâteaux differentiable norm, $C$ a nonempty closed convex subset of $E$, and $T: C \longrightarrow \mathscr{K}(E)$ a multivalued nonexpansive mapping. Suppose that $C$ is a nonexpansive retract of $E$ and that for each $u \in C$ and $t \in(0,1)$, the contraction $G_{t}$ defined by $G_{t}(x)=t T(x)+(1-t) u$ has a fixed point $x_{t} \in C$. Suppose that $\left\{x_{t}\right\}$ is diametrically regular for $T$. Then, $T$ has an endpoint if and only if $\left\{x_{t}\right\}$ is bounded as $t \longrightarrow 1$, and in this case, $\left\{x_{t}\right\}$ converges strongly as $t \longrightarrow 1$ to an endpoint of $T$.

Proof. Let $e \in \operatorname{End}(T)$. By the compactness of $T$, for each $t$ $\in(0,1)$ there exists $y_{t} \in T\left(x_{t}\right)$ such that $x_{t}=t y_{t}+(1-t) u$. Since $T$ is nonexpansive,

$$
\left\|y_{t}-e\right\|=\operatorname{dist}\left(y_{t}, T(e)\right) \leq H\left(T\left(x_{t}\right), T(e)\right) \leq\left\|x_{t}-e\right\| .
$$

This implies that

$$
\left\|x_{t}-e\right\| \leq t\left\|y_{t}-e\right\|+(1-t)\|u-e\| \leq t\left\|x_{t}-e\right\|+(1-t)\|u-e\|,
$$

and hence, $\left\|x_{t}-e\right\| \leq\|u-e\|$. Therefore $\left\{x_{t}\right\}$ is bounded. Conversely, suppose that $\left\{x_{t}\right\}$ remains bounded as $t \longrightarrow 1$. Let $\left\{t_{n}\right\}$ be a sequence in $(0,1)$ converging to 1 and put $x_{n}:=x_{t_{n}}$. For each $n \in \mathbb{N}$, let $y_{n} \in T\left(x_{n}\right)$ be such that $x_{n}=$ $t_{n} y_{n}+\left(1-t_{n}\right) u$. Then,

$\operatorname{dist}\left(x_{n}, T\left(x_{n}\right)\right) \leq\left\|x_{n}-y_{n}\right\|=\left(1-t_{n}\right)\left\|u-y_{n}\right\| \longrightarrow 0, \quad$ as $n \longrightarrow \infty$.

Since $\left\{x_{n}\right\}$ is bounded, we define $\phi: E \longrightarrow[0, \infty)$ by

$$
\phi(z)=\mu_{n}\left\|x_{n}-z\right\|^{2} .
$$

Since $\phi$ is continuous and convex, $\phi(z) \longrightarrow \infty$ as $\|z\| \longrightarrow \infty$. As $E$ is reflexive, $\phi$ attains its infimum over $C$ (cf. [21], p.79). Let $\tilde{x} \in C$ be such that

$$
\mu_{n}\left\|x_{n}-\tilde{x}\right\|^{2}=\min _{y \in C} \mu_{n}\left\|x_{n}-y\right\|^{2},
$$

and let

$$
M=\left\{x \in C: \mu_{n}\left\|x_{n}-x\right\|^{2}=\min _{y \in C} \mu_{n}\left\|x_{n}-y\right\|^{2}\right\} .
$$

Then, $M$ is nonempty because $\tilde{x} \in M$. We also obtain that $M$ is a bounded closed convex subset of $C$. Since $C$ is a nonexpansive retract of $E$, we assume that $Q$ is a nonexpansive retract of $E$ onto $C$. Then, for any $y \in E$, we have

$$
\begin{aligned}
& \mu_{n}\left\|x_{n}-y\right\|^{2} \geq \mu_{n}\left\|Q\left(x_{n}\right)-Q(y)\right\|^{2} \\
& \quad=\mu_{n}\left\|x_{n}-Q(y)\right\|^{2} \geq \mu_{n}\left\|x_{n}-\tilde{x}\right\|^{2},
\end{aligned}
$$

and hence, $\mu_{n}\left\|x_{n}-\tilde{x}\right\|^{2}=\min _{y \in E} \mu_{n}\left\|x_{n}-y\right\|^{2}$. This implies that $\tilde{x}$ is a global minimum point over all of $E$. Furthermore, $\tilde{x}$ is a unique element in $M$ by Lemma 5 . Since $T(\tilde{x})$ is compact, for each $n \geq 1$, there exists $w_{n}$ $\in T(\tilde{x})$ for $\tilde{x} \in M$ such that

$$
\left\|y_{n}-w_{n}\right\|=\operatorname{dist}\left(y_{n}, T(\tilde{x})\right) \leq H\left(T\left(x_{n}\right), T(\tilde{x})\right) \leq\left\|x_{n}-\tilde{x}\right\| .
$$

Let $\left\{w_{n_{k}}\right\}$ be a convergent subsequence of $\left\{w_{n}\right\}$. Assume that $w_{n_{k}} \longrightarrow w \in T(\tilde{x})$. For $k$ sufficiently large, we obtain from (26) and (31) that

$$
\begin{array}{r}
\left\|x_{n_{k}}-w\right\| \leq\left\|x_{n_{k}}-y_{n_{k}}\right\|+\left\|y_{n_{k}}-w_{n_{k}}\right\|+\left\|w_{n_{k}}-w\right\| \\
=\left(1-t_{n_{k}}\right)\left\|u-y_{n_{k}}\right\|+\left\|y_{n_{k}}-w_{n_{k}}\right\|+\left\|w_{n_{k}}-w\right\| .
\end{array}
$$

Thus, $\quad \mu_{n_{k}}\left\|x_{n_{k}}-w\right\|^{2} \leq \mu_{n_{k}}\left\|y_{n_{k}}-w_{n_{k}}\right\|^{2} \leq \mu_{n_{k}}\left\|x_{n_{k}}-\tilde{x}\right\|^{2}$. But $\tilde{x}$ is the unique global minimum element, $w \in M$. As we know from Lemma 5 that $M$ consists of one point, it follows that $\tilde{x}=w \in T(\tilde{x})$. We now show that $\{\tilde{x}\}=T(\tilde{x})$. Take $v \in T(\tilde{x})$ and choose $u_{n_{k}} \in T\left(x_{n_{k}}\right)$ so that $\left\|v-u_{n_{k}}\right\|=\operatorname{dist}\left(v, T\left(x_{n_{k}}\right)\right)$. Thus,

$$
\begin{aligned}
& \left\|x_{n_{k}}-v\right\| \leq\left\|x_{n_{k}}-y_{n_{k}}\right\|+\left\|y_{n_{k}}-u_{n_{k}}\right\|+\left\|u_{n_{k}}-v\right\| \\
& \quad \leq\left(1-t_{n_{k}}\right)\left\|u-y_{n_{k}}\right\|+\operatorname{diam}\left(T\left(x_{n_{k}}\right)\right) \\
& \quad+H\left(T\left(x_{n_{k}}\right), T(\tilde{x})\right) \leq\left(1-t_{n_{k}}\right)\left\|u-y_{n_{k}}\right\| \\
& \quad+\operatorname{diam}\left(T\left(x_{n_{k}}\right)\right)+\left\|x_{n_{k}}-\tilde{x}\right\| .
\end{aligned}
$$

Since $\left\{x_{n_{k}}\right\}$ is diametrically regular for $T$ and (26), we obtain that

$$
\mu_{n_{k}}\left\|x_{n_{k}}-v\right\|^{2} \leq \mu_{n_{k}}\left\|x_{n_{k}}-\tilde{x}\right\|^{2} .
$$

Since $\tilde{x}$ is the global minimum point over all of $E$, it implies that $v=\tilde{x}$, and so, $\{\tilde{x}\}=T(\tilde{x})$. On the other hand, for $\{\tilde{x}\}=T(\tilde{x})$, we obtain from (24) that

$$
\begin{aligned}
& \left\langle x_{n}-y_{n}, J\left(x_{n}-\tilde{x}\right)\right\rangle=\left\langle\left(x_{n}-\tilde{x}\right)+\left(\tilde{x}-y_{n}\right), J\left(x_{n}-\tilde{x}\right)\right\rangle \\
& \quad \geq\left\|x_{n}-\tilde{x}\right\|^{2}-\left\|y_{n}-\tilde{x}\right\|\left\|x_{n}-\tilde{x}\right\| \geq\left\|x_{n}-\tilde{x}\right\|^{2}-\left\|x_{n}-\tilde{x}\right\|^{2}=0 .
\end{aligned}
$$


It follows that

$0 \leq\left\langle x_{n}-y_{n}, J\left(x_{n}-\tilde{x}\right)\right\rangle=\left(1-t_{n}\right)\left\langle u-y_{n}, J\left(x_{n}-\tilde{x}\right)\right\rangle$.

Hence, from (26) and (36), we obtain

$$
\left\langle x_{n}-u, J\left(x_{n}-\tilde{x}\right)\right\rangle \leq\left\langle x_{n}-y_{n}, J\left(x_{n}-\tilde{x}\right)\right\rangle .
$$

Thus, for $T(\tilde{x})=\{\tilde{x}\}=M$,

$$
\mu_{n}\left\langle x_{n}-u, J\left(x_{n}-\tilde{x}\right)\right\rangle \leq \mu_{n}\left\langle x_{n}-y_{n}, J\left(x_{n}-\tilde{x}\right)\right\rangle \leq 0 .
$$

But by Lemma 4 , we have $\mu_{n}\left\langle x-\tilde{x}, J\left(x_{n}-\tilde{x}\right)\right\rangle \leq 0$ for all $x \in C$. In particular, we have

$$
\mu_{n}\left\langle u-\tilde{x}, J\left(x_{n}-\tilde{x}\right)\right\rangle \leq 0 .
$$

Combining (38) and (39), we get

$$
\mu_{n}\left\langle x_{n}-\tilde{x}, J\left(x_{n}-\tilde{x}\right)\right\rangle=\mu_{n}\left\|x_{n}-\tilde{x}\right\|^{2} \leq 0 .
$$

Therefore, there is a subsequence $\left\{x_{n_{j}}\right\}$ of $\left\{x_{n}\right\}$ which converges strongly to $\tilde{x}$. To complete the proof, suppose that there is another subsequence $\left\{x_{n_{k}}\right\}$ of \{ $\left.x_{n}\right\}$ which converges strongly to (say) $y$. Then,

$$
\begin{aligned}
& \operatorname{dist}\left(x_{n_{k}}, T\left(x_{n_{k}}\right)\right) \leq\left\|x_{n_{k}}-y_{n_{k}}\right\| \\
& \quad=\left(1-t_{n_{k}}\right)\left\|u-y_{n_{k}}\right\| \longrightarrow 0, \text { as } k \longrightarrow \infty .
\end{aligned}
$$

Since $\left\{x_{n_{k}}\right\}$ is diametrically regular for $T$, we have that $\operatorname{diam}\left(T\left(x_{n_{k}}\right)\right) \longrightarrow 0$ as $k \longrightarrow \infty$. Thus, from (41) and Lemma 6 , we get

$$
R\left(x_{n_{k}}, T\left(x_{n_{k}}\right)\right) \longrightarrow 0 \text {, as } k \longrightarrow \infty \text {. }
$$

Since $\left\{x_{n_{k}}\right\} \subseteq C, x_{n_{k}} \longrightarrow y$ and (42), we obtain from Lemma 7 that $y \in \operatorname{End}(T)$. It follows from (38) that

$$
\begin{aligned}
& \langle\tilde{x}-u, J(\tilde{x}-y)\rangle \leq 0, \\
& \langle y-u, J(y-\tilde{x})\rangle \leq 0 .
\end{aligned}
$$

Adding these two inequalities yields

$$
\langle\tilde{x}-y, J(\tilde{x}-y)\rangle=\|\tilde{x}-y\|^{2} \leq 0 .
$$

Thus, $y=\tilde{x}$. This proves the strong convergence of $\left\{x_{t}\right\}$.

Remark 10. Theorem 9 is an extension of Theorem 1 in [4] and Theorem 3.5 in [10].

It is well known that any closed convex set in Hilbert spaces is a nonexpansive retract with the proximity map as a nonexpansive retraction. Thus, we obtain the following result.
Corollary 11. Let $H$ be a real Hilbert space, $C$ a nonempty closed convex subset of $H$, and $T: C \longrightarrow \mathscr{K}(H)$ a multivalued nonexpansive mapping. Suppose that for each $u \in C$ and $t \in$ $(0,1)$, the contraction $G_{t}$ defined by $G_{t}(x)=t T(x)+(1-t) u$ has a fixed point $x_{t} \in C$. Suppose that $\left\{x_{t}\right\}$ is diametrically regular for $T$. Then, $T$ has an endpoint if and only if $\left\{x_{t}\right\}$ is bounded as $t \longrightarrow 1$, and in this case, $\left\{x_{t}\right\}$ converges strongly as $t \longrightarrow 1$ to an endpoint of $T$.

Remark 12. Corollary 11 is an extension of Corollary 1 in [4], and also, it is a non-self-mapping case of Theorem 3.6 in [10].

The following example given by Pietramala [3] (see also [10]) shows that the diametric regularity of $\left\{x_{t}\right\}$ in Theorem 9 and Corollary 11 is necessary.

Example 3. Let $X$ be the Euclidean space $\mathbb{R}^{2}$ and $C=[0,1]$ $\times[0,1]$. Let $T: C \longrightarrow \mathscr{K}(C)$ be defined by

$$
T(a, b):=\text { the closed convex hull of }\{(0,0),(a, 0),(0, b)\} \text {. }
$$

Then, $T$ is a multivalued nonexpansive mapping with $\operatorname{Fix}(T)=\{(a, b) \in C: a b=0\}$ and $\operatorname{End}(T)=\{(0,0)\}$. Fix $u \in C$. For each $t \in(0,1)$, let $x_{t}=(1-t) u$. It is easy to see that $\left\{x_{t}\right\}$ satisfies (7), and it is diametrically regular for $T$. By Corollary $11, \lim _{t \rightarrow 1} x_{t}=(0,0)$. However, if $u=(1,0)$ and $z_{t} \equiv u$, then $\left\{z_{t}\right\}$ satisfies (7) but it is not diametrically regular for $T$. Moreover, $\lim _{t \rightarrow 1} z_{t}=u \neq(0,0)$.

Recall that the inward set of $C \subseteq E$ at $x$ is defined by

$$
I_{C}(x)=\{z \in E: z=x+\lambda(y-x): y \in C, \lambda \geq 0\}
$$

It is known that if $C$ is convex, then the closure of $I_{C}(x)$ is $I_{C} \overline{(x)}=x+T_{C}(x)$ for any $x \in C$, where

$$
T_{C}(x)=\left\{y \in E: \liminf _{\lambda \rightarrow 0^{+}} \frac{d(x+\lambda y, C)}{\lambda}=0\right\} .
$$

A mapping $T: C \longrightarrow \mathscr{C} \mathscr{B}(E)$ is said to satisfy (i) weak inwardness condition if $T(x) \subset I_{C}(x)$ for all $x \in C$ and (ii) inwardness condition if $T(x) \subset I_{C}(x)$ for all $x \in C$. For details, we refer to [22].

The weak inwardness condition guarantees the existence of a fixed point of the contraction $G_{t}$ defined by (6); the weak inwardness condition for multivalued mappings is used. It has recently been shown by $\mathrm{Xu}$ [23] that if $C$ is a closed bounded convex subset of a uniformly convex Banach space $E$ and $T: C \longrightarrow \mathscr{K}(E)$ is a multivalued nonexpansive mapping satisfying the weak inwardness condition, then $T$ has a fixed point. Thus, we have the following results.

Corollary 13. Let E be a uniformly convex Banach space with a uniformly Gâteaux differentiable norm, $C$ a nonempty bounded closed convex subset of $E$, and $T: C \longrightarrow \mathscr{K}(E)$ a multivalued nonexpansive mapping. Suppose in addition that 
$T$ satisfies the weak in wardness condition. Fix $u \in C$ and let $\left\{x_{t}\right\}$ be defined by (7). If $\left\{x_{t}\right\}$ is diametrically regular for $T$, then $\left\{x_{t}\right\}$ converges strongly as $t \longrightarrow 1$ to the unique point $\tilde{x}$ in $\operatorname{End}(T)$.

Proof. Fix $u \in C$. For each $t \in(0,1)$, define the contraction $G_{t}: C \longrightarrow \mathscr{K}(E)$ by

$$
G_{t}(x)=t T(x)+(1-t) u, \quad x \in C .
$$

As it is easily seen that $G_{t}$ also satisfies the week inwardness condition: $G_{t}(x) \subset \bar{I}_{C}(x)$ for all $x \in C$, we have that $G_{t}$ has a fixed point denoted by $x_{t}$. Also, we have that the fixed point set of $T$ is nonempty. Thus, the result follows from Theorem 9.

Corollary 14. Let $H$ be a real Hilbert space, $C$ a nonempty bounded closed convex subset of $H$, and $T: C \longrightarrow \mathscr{K}(H)$ a multivalued nonexpansive mapping which satisfies the weak inwardness condition. Fix $u \in C$ and let $\left\{x_{t}\right\}$ be defined by (7). If $\left\{x_{t}\right\}$ is diametrically regular for $T$, then $\left\{x_{t}\right\}$ converges strongly as $t \longrightarrow 1$ to an endpoint of $T$.

Remark 15. Corollaries 13 and 14 are extensions of Corollaries 2 and 3 in [4], respectively.

Remark 16. In Theorem 2 of Jung [4], Browder's convergence theorem for multivalued nonexpansive mappings in a reflexive Banach space with a uniformly Gâteaux differentiable norm can be also proved. In this paper, we relaxed the endpoint condition and we then applied Lemmas 6 and 7, which is a crucial tool, to prove Browder's convergence theorem for multivalued nonexpansive mappings in uniformly convex Banach spaces with a uniformly Gâteaux differentiable norm. Therefore, the following question should be of interest.

Without the endpoint condition, can the result of Jung [4] (Theorem 2) be approached by using the notion of diametrically regular mappings?

\section{Data Availability}

No data were used to support this study.

\section{Conflicts of Interest}

The author declares that there is no conflict of interests regarding the publication of this paper.

\section{Acknowledgments}

The authors would like to thank Professor Dr. Bancha Panyanak for drawing my attention to the subject and for many useful discussions. This research was supported by Chiang Mai University.

\section{References}

[1] S. B. Nadler, "Multi-valued contraction mappings," Pacific Journal of Mathematics, vol. 30, no. 2, pp. 475-488, 1969.

[2] F. E. Browder, "Convergence of approximants to fixed points of nonexpansive non-linear mappings in Banach spaces," Archive for Rational Mechanics and Analysis, vol. 24, no. 1, pp. 82-90, 1967.

[3] P. Pietramala, "Convergence of approximating fixed points sets for multivalued nonexpansive mappings," Commentationes Mathematicae Universitatis Carolinae, vol. 32, no. 4, pp. 697-701, 1991.

[4] J. S. Jung, "Strong convergence theorems for multivalued nonexpansive nonself-mappings in Banach spaces," Nonlinear Analysis, vol. 66, no. 11, pp. 2345-2354, 2007.

[5] G. L. Acedo and H. K. Xu, "Remarks on multivalued nonexpansive mappings," Soochow Journal of Mathematics, vol. 21, no. 1, pp. 107-115, 1995.

[6] T. H. Kim and J. S. Jung, "Approximating fixed points of nonlinear map pings in Banach spaces," in Proceedings of Workshop on Fixed Point Theory, vol. 51, pp. 149-165, Kazimierz Dolny, 1997.

[7] D. R. Sahu, "Strong convergence theorems for nonexpansive type and non-self multi-valued mappings," Nonlinear Analysis: Theory, Methods \& ApplicationsNonlinear Analysis, vol. 37, no. 3, pp. 401-407, 1999.

[8] N. Shahzad and H. Zegeye, "Strong convergence results for nonself multimaps in Banach spaces," Proceedings of the American Mathematical Society, vol. 136, no. 2, pp. 539-548, 2008.

[9] Y. Song and Y. J. Cho, "Iterative approximations for multivalued nonexpansive mappings in reflexive Banach spaces," Mathematical Inequalities \& Applications, vol. 12, no. 3, pp. 611-624, 2009.

[10] B. Panyanak and S. Suantai, "Diametrically regular mappings and Browder's theorem without the endpoint condition," Numerical Functional Analysis and Optimization, vol. 41, no. 4, pp. 495-505, 2020.

[11] J. S. Jung and T. H. Kim, "Strong convergence of approximating fixed points for nonexpansive nonself-mappings in Banach spaces," Kodai Mathematical Journal, vol. 21, no. 3, pp. 259272, 1998.

[12] H. K. Xu, "Approximating curves of nonexpansive nonselfmappings in Banach spaces," Comptes Rendus de l'Académie des Sciences - Series I - Mathematics, vol. 325, no. 2, pp. 151156, 1997.

[13] S. Saejung, "Remarks on endpoints of multivalued mappings in geodesic spaces," Fixed Point Theory and Applications, vol. 2016, Article ID 52, 2016.

[14] K. Goebel and S. Reich, "Uniform convexity, hyperbolic geometry, and nonex pansive mappings," in vol. 83 of Monographs and Textbooks in Pure and Applied Mathematics, Marcel Dekker, Inc., New York, 1984.

[15] S. Reich, "Product formulas, nonlinear semigroups, and accretive operators," Journal of Functional Analysis, vol. 36, no. 2, pp. 147-168, 1980.

[16] K. S. Ha and J. S. Jung, "Strong convergence theorems for accretive operators in Banach spaces," Journal of Mathematical Analysis and Applications, vol. 147, no. 2, pp. 330-339, 1990. 
[17] S. Reich, "Nonlinear semigroups, holomorphic mappings, and integral equations," in Nonlinear Functional Analysis and Its Applications, Part 2 (Berkeley, Calif., 1983), pp. 307-324, American Mathematical Society, Providence, RI, 1986.

[18] W. Takahashi and D. H. Jeong, "Fixed point theorem for nonexpansive semigroup on Banach space," Proceedings of the American Mathematical Society, vol. 122, no. 4, pp. 11751179, 1994.

[19] B. Panyanak, "Endpoints of multivalued nonexpansive mappings in geodesic spaces," Fixed Point Theory and Applications, vol. 2015, no. 1, Article ID 147, 2015.

[20] B. Panyanak, "The demiclosed principle for multi-valued nonexpansive mappings in Banach spaces," Journal of Nonlinear and Convex Analysis, vol. 17, no. 10, pp. 2063-2070, 2016.

[21] V. Barbu and T. Precupanu, Convexity and Optimization in Banach Spaces, Editura Academiei, Bucharest, 1978, Sijthoff \& Noordhoff International Publishers, Alphen aan den Rijn, revised ed..

[22] K. Deimling, "Multivalued Differential Equations," in vol. 1 of De Gruyter Series in Nonlinear Analysis and Applications, Walter de Gruyter \& Co., Berlin, 1992.

[23] H. K. Xu, "Multivalued nonexpansive mappings in Banach spaces," Nonlinear Analysis: Theory, Methods \& Applications, vol. 43, no. 6, pp. 693-706, 2001. 